\title{
Predictors of patient dissatisfaction at 1 and 2 years after lumbar surgery
}

\author{
*Mohamed Macki, MD, MPH, ${ }^{1}$ Mohammed Ali Alvi, MBBS, ${ }^{2}$ Panagiotis Kerezoudis, MD, MS, ${ }^{2}$ \\ Shujie Xiao, MS, ${ }^{3}$ Lonni Schultz, PhD, ${ }^{4}$ Michael Bazydlo, MS, ${ }^{4}$ Mohamad Bydon, MD, ${ }^{2}$ \\ Paul Park, MD, ${ }^{5}$ and Victor Chang, MD, ${ }^{1}$ for the MSSIC Investigators
}

Departments of ${ }^{1}$ Neurosurgery, ${ }^{3}$ Internal Medicine, ${ }^{4}$ Public Health Sciences, Henry Ford Hospital, Detroit, Michigan; ${ }^{2}$ Department of Neurosurgery, Mayo Clinic, Rochester, Minnesota; and ${ }^{5}$ Department of Neurosurgery, University of Michigan, Ann Arbor, Michigan

OBJECTIVE As compensation transitions from a fee-for-service to pay-for-performance healthcare model, providers must prioritize patient-centered experiences. Here, the authors' primary aim was to identify predictors of patient dissatisfaction at 1 and 2 years after lumbar surgery.

METHODS The Michigan Spine Surgery Improvement Collaborative (MSSIC) was queried for all lumbar operations at the 1- and 2-year follow-ups. Predictors of patients' postoperative contentment were identified per the North American Spine Surgery (NASS) Patient Satisfaction Index, wherein satisfied patients were assigned a score of 1 ("the treatment met my expectations") or 2 ("I did not improve as much as I had hoped, but I would undergo the same treatment for the same outcome") and unsatisfied patients were assigned a score of 3 ("I did not improve as much as I had hoped, and I would not undergo the same treatment for the same outcome") or 4 ("I am the same or worse than before treatment"). Multivariable Poisson generalized estimating equation models were used to report adjusted risk ratios ( $\left.R_{\text {adj }}\right)$.

RESULTS Among 5390 patients with a 1-year follow-up, 22\% reported dissatisfaction postoperatively. Dissatisfaction was predicted by higher body mass index $\left(R R_{a d j}=1.07, p<0.001\right)$, African American race compared to white $\left(R_{a d j}=\right.$ $1.51, p<0.001)$, education level less than high school graduation compared to a high school diploma or equivalent $\left(R R_{a d j}\right.$ $=1.25, p=0.008)$, smoking $\left(R_{a d j}=1.34, p<0.001\right)$, daily preoperative opioid use $>6$ months $\left(R_{a d j}=1.22, p<0.001\right)$, depression $\left(R_{\mathrm{adj}}=1.31, \mathrm{p}<0.001\right)$, symptom duration $>1$ year $\left(R_{\mathrm{adj}}=1.32, \mathrm{p}<0.001\right)$, previous spine surgery $\left(R_{\mathrm{adj}}=\right.$ $1.32, p<0.001)$, and higher baseline numeric rating scale (NRS)-back pain score $\left(R_{a d j}=1.04, p=0.002\right)$. Conversely, an education level higher than high school graduation, independent ambulation $\left(R R_{a d j}=0.90, p=0.039\right)$, higher baseline NRS-leg pain score $\left(R R_{a d j}=0.97, p=0.013\right)$, and fusion surgery $\left(R_{a d j}=0.88, p=0.014\right)$ decreased dissatisfaction.

Among 2776 patients with a 2-year follow-up, $22 \%$ reported dissatisfaction postoperatively. Dissatisfaction was predicted by a non-white race, current smoking $\left(R_{\mathrm{adj}}=1.26, p=0.004\right)$, depression $\left(R_{\mathrm{adj}}=1.34, \mathrm{p}<0.001\right)$, symptom duration $>1$ year $\left(R_{a d j}=1.47, p<0.001\right)$, previous spine surgery $\left(R_{a d j}=1.28, p<0.001\right)$, and higher baseline NRS-back pain score $\left(R R_{a d j}=1.06, p=0.003\right)$. Conversely, at least some college education $\left(R R_{a d j}=0.87, p=0.035\right)$ decreased the risk of dissatisfaction.

CONCLUSIONS Both comorbid conditions and socioeconomic circumstances must be considered in counseling patients on postoperative expectations. After race, symptom duration was the strongest predictor of dissatisfaction; thus, patient-centered measures must be prioritized. These findings should serve as a tool for surgeons to identify at-risk populations that may need more attention regarding effective communication and additional preoperative counseling to address potential barriers unique to their situation.

https://thejns.org/doi/abs/10.3171/2019.8.SPINE19260

KEYWORDS lumbar; Michigan Spine Surgery Improvement Collaborative; MSSIC; NASS Patient Satisfaction Index; North American Spine Surgery

\footnotetext{
ABBREVIATIONS ASA = American Society of Anesthesiologists; BCBSM = Blue Cross Blue Shield of Michigan; BCN = Blue Care Network; BMI = body mass index; GED = General Educational Development; GEE = generalized estimating equation; MCID = minimum clinically important difference; MSSIC = Michigan Spine Surgery Improvement Collaborative; NASS = North American Spine Society; NRS = numeric rating scale; ODI = Oswestry Disability Index; PHQ-2 = Patient Health Questionnaire-2; PRO = patient-reported outcome; PSI = Patient Satisfaction Index; $\mathrm{RR}_{\mathrm{adj}}=$ adjusted risk ratio; $\mathrm{SSI}$ = surgical site infection.

SUBMITTED March 6, 2019. ACCEPTED August 28, 2019.
}

INCLUDE WHEN CITING Published online November 22, 2019; DOI: 10.3171/2019.8.SPINE19260.

${ }^{*}$ M.M. and M.A.A. share first authorship. 
$\mathrm{T}$ HE Patient Protection and Affordable Care Act of 2010 required the Secretary of the Department of Health and Human Services (HHS) to establish the National Strategy for Quality Improvement in Health Care (National Quality Strategy). This directive was intended to provide high-quality yet affordable healthcare for all Americans. As one of ten aims for this newly developed National Quality Strategy in the 2011 Report to Congress, the HHS defined the Public Reporting aim "to compare costs, review treatment outcomes, and assess patient satisfaction." 42 This initiative has subsequently facilitated the transition from a fee-for-service to a pay-for-performance healthcare model, which requires hospitals and providers alike to prioritize patient-centered outcomes. Surgical facilities must therefore emphasize postoperative satisfaction as one of the key metrics of quality assessment. ${ }^{10,27,40}$

Several studies have focused on patient-reported outcomes (PROs) as metrics of patient satisfaction., ${ }^{9,43,44}$ Surveys like the Hospital Consumer Assessment of Healthcare Providers and Systems (HCAHPS) were developed to objectify patient satisfaction, but that instrument's 29 questions target broader patient experiences that lack applicability to surgical specialties. ${ }^{14}$ In their article on the evolution of HCAHPS in spine surgery, Malpani et al. concluded that the metric links hospital remuneration to patient satisfaction. ${ }^{35}$ However, the questionnaire neglects an emphasis on PROs, as other spine surgeons have noted with HCAHPS. ${ }^{31,34}$ More specific metrics are necessary to predict patient satisfaction with surgery, but well-validated PROs, like the numeric rating scales (NRSs), EQ5D, Oswestry Disability Index (ODI), and SF-12, may not adequately capture patient-centered experiences. ${ }^{24}$ These published questionnaires can be costly, difficult, and burdensome to administer. As a result, the North American Spine Surgery (NASS) Patient Satisfaction Index (PSI) was developed to capture a yes/no binary response to "I would undergo the same treatment again."11 Patient satisfaction has emerged as a proxy for healthcare quality because of its ease of collection as a response to a single question. Satisfaction metrics have increasingly governed medical finances when health maintenance organizations or health insurance companies negotiate prices for the purchase of healthcare. Thus, in this study, we aimed to elicit predictors of the NASS PSI at 1 and 2 years following lumbar surgeries registered in a statewide database.

\section{Methods}

Approval for this study was received from the Henry Ford Hospital Institutional Review Board. The source population was provided by the Michigan Spine Surgery Improvement Collaborative (MSSIC). ${ }^{7}$ The registry was established by Blue Cross Blue Shield of Michigan (BCBSM) and Blue Care Network (BCN) health insurance companies as part of the Value Partnerships program-a collection of clinical enterprises to improve statewide patient care. The MSSIC represents a BCBSM/BCN-funded Collaborative Quality Initiative in both the hospital and private practice settings. All participating centers must 1) perform a minimum of 200 spinal procedures annually and 2) assign at least one neurosurgeon and one orthope- dic surgeon to act as surgeon champions. A surgeon from each specialty must have privileges at any given MSSIC site in order to maintain equal representation in collaborative activities (e.g., conference calls, quarterly meetings, and committees); this will ensure that spine practice and thus outcomes reflect practice patterns from both training perspectives. A few exceptions can exist if one specialty is more dominant in a certain institution as long as the case volume is sufficient. Healthcare providers are not restricted to BCBSM/BCN subscribers. Housed at the Henry Ford Hospital, the MSSIC Coordinating Center trains abstractors at participating centers and monitors data validity, which involves routine data audits as well as three meetings with the entire collaborative throughout the year. Only the surgeon has access to his or her own data, which otherwise consist of de-identified individual-level information for the purposes of quality-improvement comparisons. Consistent with the "lift all boats" mission statement, the MSSIC prohibits the advertisement of outcome comparisons among the different healthcare participants.

For this study, the MSSIC was queried for all lumbar operations undertaken for a primary diagnosis of lumbar stenosis, spondylolisthesis, or lumbar disc herniation. The MSSIC focuses on spinal operations performed for elective, degenerative indications; urgent or emergent classifications of operations are not collected. Surgeries for neoplasms, trauma, or deformity are similarly excluded, as are pure thoracic cases. Preoperative demographic data, intraoperative parameters, and 90-day postoperative complications from February 24, 2014, to October 5, 2018, were abstracted from the MSSIC database. The primary outcome measure reflected the patients' postoperative contentment as defined by the NASS PSI, wherein satisfied patients were defined by a score of 1 ("the treatment met my expectations") or 2 ("I did not improve as much as I had hoped, but I would undergo the same treatment for the same outcome") and unsatisfied patients were defined by a score of 3 ("I did not improve as much as I had hoped, and I would not undergo the same treatment for the same outcome") or 4 ("I am the same or worse than before treatment"). ${ }^{11}$ Thus, the PSI was converted into a dichotomous outcome with analysis following a Boolean data type: satisfaction (score 1 or 2) versus dissatisfaction (score 3 or 4). Patient satisfaction was determined by surveys completed at the 1- and 2-year follow-ups using phone calls, mail, and/or web portal. Preoperative baseline disability/pain scales included the ODI, NRS-leg pain, and NRS-back pain. Other PROs included the minimum clinically important difference (MCID) in the ODI for low-back pain, which refers to a single cut-point that would represent a change in ODI (treated as a binary outcome). Other measures included depression as defined by the Patient Health Questionnaire-2 (PHQ-2), a measure of the frequency of depressed mood and anhedonia over the past 2 weeks. ${ }^{33}$ The survey is given to all patients at both preoperative and postoperative clinic visits.

All adverse events are defined within 90 postoperative days - a timeframe established by the 90-day bundled payments by third-party payers. Complications within 90 postoperative days provided in the MSSIC registry include readmission after hospital discharge, return to the operat- 
ing room, and urinary retention ([re]placement of a Foley catheter after surgery). Revision surgeries within 90 postoperative days are, therefore, not counted as index operations in the cohort but rather as a return to the operating room. If the revision surgery occurs beyond 90 days, then the first procedure is documented as a previous spine surgery. Surgical site infection (SSI) must involve only skin and subcutaneous tissue of the incision, and patients must have at least one of the following: 1) purulent drainage from the superficial incision; 2) organisms isolated from an aseptically obtained culture from the superficial incision or subcutaneous tissue; 3 ) superficial incision that is deliberately opened by a surgeon, attending physician, or other designee and is culture positive or not cultured, and the patient has at least one sign or symptom of SSI (pain or tenderness, localized swelling, erythema, or heat); or 4) a superficial incisional SSI diagnosis by the surgeon or attending physician or other designee. "At least one complication" refers to any one of the following: deep venous thrombosis, urinary tract infection, urinary retention, ileus, pulmonary embolism, myocardial infarction, death, new neurological deficit, prolonged intubation $>96$ hours, SSI, unplanned return to the operating room (on initial admission), readmission in 90 days, return to the operating room after discharge within 90 days, surgical site hematoma, wound dehiscence, durotomy, dysphagia, or cerebrospinal fluid leakage. PROs are collected 1 year and 2 years after surgery, with abstractors collecting information from the electronic medical record systems as well as standardized patient questionnaires.

\section{Statistical Analysis}

Satisfied patients were compared to unsatisfied patients, and we report variables as frequencies (percentages), means \pm standard deviations, or medians (interquartile ranges). The chi-square test was used to compare binary outcomes. Median or ordinal variables were compared with a Wilcoxon rank-sum test (Mann-Whitney U-test), whereas means of continuous outcomes were compared with a t-test. Poisson generalized estimating equation (GEE) models were fitted to the data to estimate the effect of unsatisfied patients at the 1- and 2-year follow-ups. These models account for the possibility of correlation among patients undergoing surgery within the same hospital. The Poisson distribution was used rather than the binomial distribution because the outcome of dissatisfaction was not rare enough for odds ratios to approximate the risk ratios. Thus, associations between prognostic factors and primary outcomes were computed as adjusted risk ratios $\left(\mathrm{RR}_{\mathrm{adj}}\right)$ in the multivariable analysis. Risk ratios are reported with $95 \%$ confidence intervals when applicable. Statistical significance was set at $p<0.05$. The multivariable analysis was performed on complete cases, i.e., those with data available for every variable in the models.

\section{Results}

Of the 16,725 patients who had undergone elective lumbar surgery, 8428 did not have PROs available and 2907 patients had missing covariables studied in this analysis at 1 year. A net of 5390 patients had satisfaction data for
1 year after lumbar surgery: $22 \%$ of patients $(n=1164)$ reported dissatisfaction postoperatively (PSI score 3 or 4), whereas $78 \%$ of patients $(n=4226)$ reported satisfaction postoperatively (PSI score 1 or 2; Table 1). Unsatisfied patients as compared to satisfied patients comprised a statistically significantly higher percentage of African Americans, current smokers, and persons with a high school diploma/General Educational Development (GED) or less education, daily preoperative opioid use $>6$ months, diabetes mellitus, coronary artery disease, depression, symptom duration $>1$ year, previous spine surgery, nonprivate insurance, American Society of Anesthesiologists (ASA) class III and IV, and multilevel versus single-level surgery. In terms of postoperative outcomes, unsatisfied versus satisfied patients had a higher percentage of 90-day readmissions, returns to the operating room within 90 days, urinary retention, SSIs, and at least 1 complication. On the other hand, unsatisfied patients made up lower percentages of those with independent ambulation preoperatively, lumbar disc herniations preoperatively, discharge to home, and an MCID in ODI at 1 year postoperatively. Of note, statistically significant yet not clinically meaningful differences such as higher body mass index (BMI), baseline ODI, baseline NRS-back pain scores, and hospital lengths of stay were detected among continuous and ordinal values.

After a multivariable GEE regression (Table 2), dissatisfaction at the 1-year follow-up was predicted by an African American race compared to white, an education level below high school graduation compared to high school diploma or equivalent, current smoking, daily preoperative opioid use $>6$ months, depression, symptom duration $>1$ year, and previous spine surgery. Conversely, an education level above high school graduation, independent ambulation, and fusion surgery versus decompression alone decreased the risk of dissatisfaction with surgery. Lastly, the continuous variables of increasing BMI, baseline NRSback pain score, and baseline NRS-leg pain score conferred nominal yet statistically significant risk ratios.

Of the 10,335 patients who had undergone elective lumbar surgery, 5985 did not have PROs available and 1574 patients had missing covariables studied in this analysis at 2 years. A net of 2776 patients had satisfaction data for 2 years after lumbar surgery: $22 \%$ of patients $(n=614)$ reported dissatisfaction postoperatively (PSI score 3 or 4), whereas $78 \%$ of patients $(n=2162)$ reported satisfaction postoperatively (PSI score 1 or 2; Table 3). Unsatisfied patients as compared to satisfied patients included a statistically significantly higher percentage of non-white races, current smokers, and persons with a high school diploma/ GED or less education, daily preoperative opioid use > 6 months, coronary artery disease, depression, symptom duration $>1$ year, previous spine surgery, ASA physical status class 3, fusion versus decompression alone, and multilevel versus single-level surgery. In terms of postoperative outcomes, unsatisfied patients included a higher percentage of those with 90-day readmissions, returns to the operating room within 90 days, SSIs, and at least 1 complication. On the other hand, unsatisfied patients had lower percentages of those with an education level above a high school diploma or equivalent, independent ambula- 
TABLE 1. Factors associated with patient satisfaction at 1 year after lumbar surgery

\begin{tabular}{|c|c|c|c|}
\hline Variable & Satisfaction & Dissatisfaction & $p$ Value \\
\hline \multicolumn{4}{|l|}{ Preop } \\
\hline No. of patients & 4226 & 1164 & \\
\hline Age in yrs & $62.8 \pm 12.7$ & $63.1 \pm 13.0$ & 0.450 \\
\hline Male sex & $2115(50 \%)$ & $574(49 \%)$ & 0.657 \\
\hline $\mathrm{BMI}$ in $\mathrm{kg} / \mathrm{m}^{2}$ & $30.8 \pm 6.1$ & $31.9 \pm 6.8$ & $<0.001$ \\
\hline \multicolumn{4}{|l|}{ Race } \\
\hline White & $3878(92 \%)$ & $1013(87 \%)$ & $<0.001$ \\
\hline African American & $183(4 \%)$ & $103(9 \%)$ & \\
\hline Other & $165(4 \%)$ & $48(4 \%)$ & \\
\hline \multicolumn{4}{|l|}{ Education } \\
\hline Less than high school diploma/GED & $167(4 \%)$ & $85(7 \%)$ & $<0.001$ \\
\hline High school diploma/GED & $1929(46 \%)$ & $606(52 \%)$ & \\
\hline At least some college & $1487(35 \%)$ & $370(32 \%)$ & \\
\hline At least some postcollege & $643(15 \%)$ & $103(9 \%)$ & \\
\hline Current smoker & $511(12 \%)$ & $219(19 \%)$ & $<0.001$ \\
\hline Diabetes & $901(21 \%)$ & $280(24 \%)$ & 0.046 \\
\hline Coronary artery disease & $580(14 \%)$ & $193(17 \%)$ & 0.014 \\
\hline Deep venous thrombosis & $264(6 \%)$ & $77(7 \%)$ & 0.648 \\
\hline Osteoporosis & $466(11 \%)$ & $137(12 \%)$ & 0.476 \\
\hline Independently ambulatory & $3467(82 \%)$ & $883(76 \%)$ & $<0.001$ \\
\hline Depression per PHQ-2 & $1230(29 \%)$ & $484(42 \%)$ & $<0.001$ \\
\hline Symptom duration >1 yr & $2667(63 \%)$ & $855(73 \%)$ & $<0.001$ \\
\hline Previous spine surgery & $1713(41 \%)$ & $606(52 \%)$ & $<0.001$ \\
\hline Private insurance & $1887(45 \%)$ & $448(38 \%)$ & $<0.001$ \\
\hline ASA class & & & $<0.001$ \\
\hline I & $95(2 \%)$ & $16(1 \%)$ & \\
\hline II & $2028(48 \%)$ & $469(40 \%)$ & \\
\hline III & $2047(48 \%)$ & $657(56 \%)$ & \\
\hline IV & $55(1 \%)$ & $22(2 \%)$ & \\
\hline Data missing & $1(<1 \%)$ & 0 & \\
\hline \multicolumn{4}{|l|}{ Lumbar pathology } \\
\hline Disc herniation & $2609(62 \%)$ & $669(57 \%)$ & 0.008 \\
\hline Spondylolisthesis & $1764(42 \%)$ & $453(39 \%)$ & 0.083 \\
\hline Stenosis & $3482(82 \%)$ & $958(82 \%)$ & 0.942 \\
\hline Baseline ODI & $46.0 \pm 15.9$ & $49.7 \pm 16.3$ & $<0.001$ \\
\hline Baseline NRS-back pain score & $7(5,9)$ & $8(6,9)$ & $<0.001$ \\
\hline Baseline NRS-leg pain score & $7(5,9)$ & $8(5,9)$ & 0.082 \\
\hline Fusion (vs decompression) & $2163(51 \%)$ & $612(53 \%)$ & 0.399 \\
\hline Multiple levels (vs single level) & $2144(51 \%)$ & $652(56 \%)$ & 0.001 \\
\hline \multicolumn{4}{|l|}{ Postop } \\
\hline Hospital length of stay & $2(1,3)$ & $2(1,4)$ & $<0.001$ \\
\hline Discharge home & $3766(89 \%)$ & $972(84 \%)$ & $<0.001$ \\
\hline Readmitted w/in 90 days & $197(5 \%)$ & $105(9 \%)$ & $<0.001$ \\
\hline Returned to OR w/in 90 days & $85(2 \%)$ & $45(4 \%)$ & $<0.001$ \\
\hline Urinary retention & $314(7 \%)$ & $113(10 \%)$ & 0.011 \\
\hline SSI & $47(1 \%)$ & $32(3 \%)$ & $<0.001$ \\
\hline At least 1 complication & $851(20 \%)$ & $310(27 \%)$ & 0.001 \\
\hline MCID in ODI at $1 \mathrm{yr}$ & $2420 / 3259(74 \%)$ & $212 / 907(23 \%)$ & $<0.001$ \\
\hline
\end{tabular}


TABLE 2. Multivariable Poisson regression for unsatisfied patients at 1 and 2 years postoperatively

\begin{tabular}{|c|c|c|c|c|}
\hline \multirow[b]{2}{*}{ Variable } & \multicolumn{2}{|c|}{1 Yr Postoperatively $(n=5390)$} & \multicolumn{2}{|c|}{2 Yrs Postoperatively $(n=3776)$} \\
\hline & Adjusted RR (95\% Cl) & $\mathrm{p}$ Value & Adjusted RR $(95 \% \mathrm{Cl})$ & p Value \\
\hline Age in 5-yr increments & $1.02(0.99,1.05)$ & 0.137 & $1.02(0.99,1.06)$ & 0.149 \\
\hline Male sex & $1.00(0.87,1.14)$ & 0.954 & $1.02(0.91,1.16)$ & 0.704 \\
\hline $\mathrm{BMI}$ in $\mathrm{kg} / \mathrm{m}^{2}$ in 5 -unit increments & $1.07(1.03,1.11)$ & $<0.001$ & $1.01(0.96,1.06)$ & 0.673 \\
\hline \multicolumn{5}{|l|}{ Race } \\
\hline White & Reference & & Reference & \\
\hline African American & $1.51(1.29,1.78)$ & $<0.001$ & $1.48(1.12,1.94)$ & 0.006 \\
\hline Other & $1.01(0.82,1.26)$ & 0.909 & $1.37(1.08,1.73)$ & 0.009 \\
\hline \multicolumn{5}{|l|}{ Education } \\
\hline Less than high school diploma/GED & $1.25(1.06,1.47)$ & 0.008 & $0.97(0.75,1.26)$ & 0.813 \\
\hline High school diploma/GED & Reference & & Reference & \\
\hline At least some college & $0.90(0.83,0.96)$ & 0.003 & $0.87(0.76,0.99)$ & 0.035 \\
\hline At least some postcollege & $0.70(0.60,0.82)$ & $<0.001$ & $0.86(0.70,1.06)$ & 0.162 \\
\hline Current smoking & $1.34(1.18,1.52)$ & $<0.001$ & $1.26(1.08,1.48)$ & 0.004 \\
\hline Preop daily opioid use $>6$ mos & $1.22(1.10,1.34)$ & $<0.001$ & $1.16(0.99,1.35)$ & 0.063 \\
\hline Diabetes & $0.96(0.87,1.07)$ & 0.451 & $1.02(0.90,1.15)$ & 0.800 \\
\hline Coronary artery disease & $1.10(0.97,1.25)$ & 0.136 & $1.15(0.95,1.38)$ & 0.154 \\
\hline Deep venous thrombosis & $0.87(0.71,1.07)$ & 0.162 & $0.81(0.62,1.05)$ & 0.115 \\
\hline Osteoporosis & $1.00(0.84,1.20)$ & 0.990 & $0.91(0.77,1.08)$ & 0.294 \\
\hline Independently ambulatory & $0.90(0.82,1.00)$ & 0.039 & $0.88(0.73,1.07)$ & 0.193 \\
\hline Depression per PHQ-2 & $1.31(1.21,1.42)$ & $<0.001$ & $1.34(1.15,1.56)$ & $<0.001$ \\
\hline Symptom duration $>1 \mathrm{yr}$ & $1.32(1.18,1.48)$ & $<0.001$ & $1.47(1.22,1.76)$ & $<0.001$ \\
\hline Previous spine surgery & $1.32(1.16,1.50)$ & $<0.001$ & $1.28(1.11,1.48)$ & $<0.001$ \\
\hline Private insurance & $0.93(0.85,1.02)$ & 0.135 & $0.88(0.74,1.04)$ & 0.138 \\
\hline Higher baseline ODI & $1.01(0.96,1.07)$ & 0.633 & $1.03(0.97,1.10)$ & 0.326 \\
\hline Higher baseline NRS-back pain score & $1.04(1.01,1.07)$ & 0.002 & $1.06(1.02,1.10)$ & 0.003 \\
\hline Higher baseline NRS-leg pain score & $0.97(0.95,0.99)$ & 0.013 & $0.97(0.94,1.00)$ & 0.081 \\
\hline Fusion (vs decompression) & $0.88(0.79,0.97)$ & 0.014 & $0.98(0.87,1.11)$ & 0.776 \\
\hline Multiple levels (vs single level) & $1.07(0.96,1.20)$ & 0.202 & $1.05(0.95,1.16)$ & 0.334 \\
\hline
\end{tabular}

tion, discharge to home, and an MCID in the ODI at 2 years postoperatively. Of note, the following statistically significant yet not clinically meaningful differences were detected among continuous and ordinal values: mean BMI, mean baseline ODI, median baseline NRS-back pain, and mean length of inpatient hospital stay.

Following a multivariable GEE regression (Table 2), dissatisfaction at the 2-year follow-up was predicted by a non-white race, current smoking, depression, symptom duration $>1$ year, and previous spine surgery. Conversely, at least some college education decreased the risk of being unsatisfied with surgery. Again, the continuous variable a higher baseline NRS-back pain conferred a nominal, yet statistically significant, risk ratio.

From the multivariable GEE regression, an education level of at least some college, current smoking, depression, symptom duration $>1$ year, previous spine surgery, higher baseline NRS-back pain score maintained statistical significance with dissatisfaction at both 1 and 2 years postoperatively. Above all else, an African American race in comparison to a white race followed by symptom du- ration $>1$ year remained the strongest predictors of dissatisfaction at both time points. However, the following associations with dissatisfaction at 1 year were no longer statistically significant at 2 years: higher BMI, education less than a high school diploma/GED, some postcollege education compared to a high school diploma/GED, preoperative daily opioid use $>6$ months, independent ambulation, higher baseline NRS-leg pain score, and fusion versus decompression alone. On the contrary, among variables not related to dissatisfaction at 1 year, "other" races in comparison to white represented the sole prognostic factor that statistically significantly increased the risk of dissatisfaction by $37 \%$ at 2 years.

\section{Discussion}

\section{Key Results}

In the current study, a statewide spine registry was queried for all lumbar operations to identify factors associated with patient dissatisfaction at the 1- and 2-year follow-ups. Multivariable analysis showed that lower satisfaction at 1 
TABLE 3. Factors associated with patient satisfaction at 2 years after lumbar surgery

\begin{tabular}{|c|c|c|c|}
\hline Variable & Satisfaction & Dissatisfaction & $\mathrm{p}$ Value \\
\hline \multicolumn{4}{|l|}{ Preop } \\
\hline No. of patients & 2162 & 614 & \\
\hline Age & $62.2 \pm 12.9$ & $63.2 \pm 13.3$ & 0.093 \\
\hline Male sex & $1052(49 \%)$ & $298(49 \%)$ & 0.957 \\
\hline $\mathrm{BMl}$ in $\mathrm{kg} / \mathrm{m}^{2}$ & $31.0 \pm 6.1$ & $31.6 \pm 6.6$ & 0.044 \\
\hline Race & & & $<0.001$ \\
\hline White & $2007(93 \%)$ & $532(87 \%)$ & \\
\hline African American & $89(4 \%)$ & $53(9 \%)$ & \\
\hline Other & $66(3 \%)$ & $29(5 \%)$ & \\
\hline Education & & & 0.002 \\
\hline Less than high school diploma/GED & $84(4 \%)$ & $31(5 \%)$ & \\
\hline High school diploma/GED & $972(45 \%)$ & $320(52 \%)$ & \\
\hline At least some college & $780(36 \%)$ & $193(31 \%)$ & \\
\hline At least some postcollege & $326(15 \%)$ & $70(11 \%)$ & \\
\hline Current smoker & $244(11 \%)$ & $102(17 \%)$ & $<0.001$ \\
\hline Diabetes & $425(20 \%)$ & $139(23 \%)$ & 0.105 \\
\hline Coronary artery disease & $267(12 \%)$ & $96(16 \%)$ & 0.033 \\
\hline Deep venous thrombosis & $135(6 \%)$ & $37(6 \%)$ & 0.843 \\
\hline Osteoporosis & $218(10 \%)$ & $62(10 \%)$ & 0.992 \\
\hline Independently ambulatory & $1802(83 \%)$ & $472(77 \%)$ & $<0.001$ \\
\hline Depression per PHQ-2 & $593(27 \%)$ & $251(41 \%)$ & $<0.001$ \\
\hline Symptom duration $>1 \mathrm{yr}$ & $1373(64 \%)$ & $468(76 \%)$ & $<0.001$ \\
\hline Previous spine surgery & $860(40 \%)$ & $316(51 \%)$ & $<0.001$ \\
\hline Private insurance & $1033(48 \%)$ & $243(40 \%)$ & 0.001 \\
\hline ASA class & & & $<0.001$ \\
\hline I & $54(2 \%)$ & $6(1 \%)$ & \\
\hline$\|$ & $1104(51 \%)$ & $251(41 \%)$ & \\
\hline III & $974(45 \%)$ & $349(57 \%)$ & \\
\hline IV & $29(1 \%)$ & $8(1 \%)$ & \\
\hline Missing data & $1(<1 \%)$ & & \\
\hline \multicolumn{4}{|l|}{ Lumbar pathology } \\
\hline Disc herniation & $1183(55 \%)$ & $319(52 \%)$ & 0.225 \\
\hline Spondylolisthesis & $825(38 \%)$ & $230(37 \%)$ & 0.752 \\
\hline Stenosis & $1674(77 \%)$ & $460(75 \%)$ & 0.193 \\
\hline Baseline ODI & $45.7 \pm 15.5$ & $49.7 \pm 16.0$ & $<0.001$ \\
\hline Baseline NRS-back pain score & $7(5,9)$ & $8(7,9)$ & $<0.001$ \\
\hline Baseline NRS-leg pain score & $7(5,9)$ & $7(5,9)$ & 0.346 \\
\hline Fusion (vs decompression) & $1040(48 \%)$ & $326(53 \%)$ & 0.029 \\
\hline Multiple levels (vs single level) & $1069(49 \%)$ & $332(54 \%)$ & 0.043 \\
\hline \multicolumn{4}{|l|}{ Postop } \\
\hline Hospital length of stay & $2(1,3)$ & $2(1,4)$ & $<0.001$ \\
\hline Discharge home & $1946(90 \%)$ & $517(84 \%)$ & $<0.001$ \\
\hline Readmitted w/in 90 days & $102(5 \%)$ & $52(8 \%)$ & $<0.001$ \\
\hline Returned to OR w/in 90 days & $38(2 \%)$ & $29(5 \%)$ & $<0.001$ \\
\hline Urinary retention & $189(9 \%)$ & $66(11 \%)$ & 0.126 \\
\hline SSI & $31(1 \%)$ & $18(3 \%)$ & 0.013 \\
\hline At least 1 complication & $462(21 \%)$ & $168(27 \%)$ & 0.002 \\
\hline MCID in ODI at 2 yrs & $1053 / 1445(73 \%)$ & $88 / 422(21 \%)$ & $<0.001$ \\
\hline
\end{tabular}

Values expressed as mean \pm standard deviation, number (\%), or median (IQR). Boldface type indicates statistical significance. 
year was associated with higher BMI, African American race, lower level of education, current smoking, daily preoperative opioid use $>6$ months, dependent ambulation, depression, symptom duration $>1$ year, previous spine surgery, greater baseline back pain, less baseline leg pain, and decompressions alone versus fusions. Dissatisfaction at 2 years was associated with non-white race, education level less than a high school diploma or equivalent, current smoking, depression, symptom duration $>1$ year, previous spine surgery, and greater baseline back pain. Identifying these variables will help to set realistic postoperative expectations and thus increase patient satisfaction after lumbar surgery.

\section{Interpretation}

African American race was the strongest predictor of lower satisfaction in both the 1-year and 2-year multivariable analyses. Preoperative differences that may confound the association between race and postoperative dissatisfaction have been described elsewhere. ${ }^{17,21,25,36,37}$ A few examples include the perception of pain, coping with depression, and the prevalence of the metabolic syndrome-a cluster of conditions that increases the risk of heart disease, stroke, and type 2 diabetes - among African Americans. The multivariable Poisson regression controlled for these potential confounders in the current analysis. Note that the correlation between African Americans and dissatisfaction is not unique to our study. Elsamadicy et al., in their study of 345 patients who had undergone elective lumbar surgery, demonstrated that African American patients were more likely to report lower satisfaction with their surgery at 3 months and at 1 year. ${ }^{15}$ In their meta-analysis of 128,635 patients who had undergone spine surgery, Schoenfeld et al. showed that non-white patients had a higher risk of an unfavorable outcome than their white counterparts. ${ }^{39}$ In a corollary study of the Spine Patient Outcomes Research Trial (SPORT), Schoenfeld et al. documented better PROs in white patients than in African American patients regardless of the treatment arm (surgical intervention and nonoperative management). ${ }^{38}$ Moreover, white patients were more likely to undergo surgery than the non-white patients. This finding points to a possible disconnect between African Americans and the healthcare field. In the article "Differences in expectations of outcome mediate African American/white patient differences in "willingness' to consider joint replacement," a survey by our orthopedic surgery colleagues, African American patients as compared to their white counterparts were less "willing" to consider joint replacement because of a statistically significantly decreased familiarity with the operation as well as perceptions of a longer expected hospital stay, functional disability, and pain after joint replacement. ${ }^{26}$ Similarly, our results with neurosurgical patients may reflect a potential disparity in operative outcomes, complications, and postoperative care (especially rehabilitation) - all of which can influence long-term satisfaction. Objective measures of communication between surgeons and African American patients warrant further investigation.

In the current study, an education less than high school graduation was also associated with increased risk of patient dissatisfaction at 1 year. Insights from the cardio- vascular literature have revealed that health behaviors, namely smoking, low vegetable intake, and little physical activity, explained up to $54 \%$ of the relative difference between primary and higher educational levels in deaths related to heart disease. ${ }^{29}$ Extrapolating these data to spine surgery, lower-education patients may be constitutionally ill-equipped to overcome the morbidity associated with a lumbar procedure and rigorous postoperative rehabilitation. ${ }^{4,29,41}$ This highlights a potential healthcare disparity in patients with lower levels of education. Whether this result reflects consequences unique to certain socioeconomic factors linked to education (or the lack thereof in this instance) or an increased comorbidity burden in this population warrants further investigation as well.

This study also demonstrated that a history of depression was associated with dissatisfaction at 1 and 2 years. Some studies have hypothesized that decreased motivation for wellness via appropriate health maintenance, notwithstanding recovery from postoperative morbidity, as a possible cause of dissatisfaction with surgery. $2,5,6,8,13,18,30,32$ Relatedly, the implications of chronic pain, or symptom duration $>1$ year, understandably increased the risk of dissatisfaction by $32 \%$ at the 1-year follow-up and $47 \%$ at the 2-year follow-up in the current study. Following a population study using the Canadian Community Health Survey in a sample of 118,533 household residents, Currie and Wang found that back pain was the strongest predictor of major depression in a multivariable logistic regression, which led to the conclusion that "the combination of chronic back pain and major depression was associated with greater disability than either condition alone."12 From an anatomical perspective, longer symptom duration may equate to longer compression to the delicate neural elements that are less likely to recover to baseline after decompression. Dissecting the location of symptoms also plays an important role in determining predictors of dissatisfaction. After the 1- and 2-year follow-ups in our study, patients with predominant back pain had an increased risk of dissatisfaction, whereas predominant leg pain decreased the risk of dissatisfaction. Unfortunately, these patient-reported measures do not correlate with subjective improvement postoperatively according to a multimodal assessment after spine surgery by King et al. ${ }^{28}$ Among the 28 patients choosing operative management in that study, decisional regret in less than $20 \%$ of the population did not align with outcome instrument results. Thus, the interplay of decisional regret and dissatisfaction requires further research to isolate potential confounders.

We also observed that certain operative factors can influence both patient-reported and clinical outcomes in the long term. Our study demonstrated that fusion was associated with a higher possibility of patient satisfaction at 1 year. Current literature on the role of instrumented fusion, particularly in cases of low-grade degenerative spondylolisthesis and/or lumbar spinal stenosis, has been a point of controversy. ${ }^{19,20,23}$ A recent meta-analysis of 5 randomized clinical trials showed no benefit from fusion in terms of ODI score and patient satisfaction at 2 years. While instrumented fusion may prevent a recurrence of symptoms by addressing the instability in the spinal segment, prior randomized clinical trials comparing spinal decompression 
plus fusion versus spinal decompression alone revealed only moderately improved PROs that may be attributable to preoperative symptoms. ${ }^{20,23}$ However, several independent observational studies have demonstrated that the addition of fusion conferred superior clinical outcomes and PROs. ${ }^{1,3,16}$ All these findings speak to the importance of tailoring the appropriate operation to the primary spinal pathology, which should not be muddled with historical concerns of "invasive surgery" (e.g., fusions) compromising patient satisfaction.

Lastly, the association of dissatisfaction with increasing BMI and lower baseline NRS-leg pain scores lost statistical significance at 2 years compared to the 1-year results likely because of the marginally significant values in the regression model, which mirror the phenomena with these same continuous and ordinal variables in the univariable analysis (Tables 1 and 3). Another possible mathematical explanation for the change in statistical significance from 1 to 2 years could be a reduction in power attributable to the smaller sample size. However, the literature has provided a biological alternative to the differing effect of an increasing BMI between 1 and 2 years postoperatively. In a study on obesity and lumbar decompression, Gepstein et al. found that the number of "very dissatisfied patients" was higher among obese patients. ${ }^{22}$ This difference was attributed to body habitus limitations in activities of daily living as well as perceptions of pain during the outpatient visits. However, with appropriate follow-up, obese patients eventually reported satisfactory results after requiring a longer duration of therapy and therefore recovery.

\section{Study Limitations}

Our cohort consisted of patients enrolled in a single statewide registry relying on patient-reported data as well as chart abstraction. Large multicenter registries are not without their shortcomings. First, a selection bias should be considered when patients choose to continue to participate in data collection after surgery versus those lost to follow-up. According to an MSSIC study on predictors of lumbar spine patients completing the 1-year PROs, spondylolisthesis or stenosis (vs herniated disc), leg (vs back) pain, multilevel surgery, and discharge to rehabilitation increased response rates at 1 year. ${ }^{45}$ Second, incomplete data were assumed to be missing at random; therefore, patients with missing covariates in the multivariable regression were dropped from the statistical analysis, which may have introduced additional bias into the results.

Another shortcoming of large multicenter registries includes a limited number of variables collected. One example is the surgical approach: open versus minimally invasive. Because of the inconsistent definitions and lack of consensus regarding what is considered minimally invasive, this information is not currently collected in the MSSIC. Similarly, surgeon preference to pursue surgery is not captured in the index multiinstitutional registry. Given the diverse set of clinical diagnoses in our present analysis, the decision to perform surgery equals the sum of the clinical presentation and radiographic picture of a given patient. This introduces an element of subjectivity based on surgeon interpretation for operative need, which has implications for the findings seen here.
Also, multiinstitutional databases have limited data points. Thus, while surrogate markers of the comorbidity burden, such as the modified Frailty Index and Charlson Comorbidity Index, would strengthen the statistical analysis, these well-validated composite scoring systems were not available in the MSSIC. Instead, the ASA classification was included in the Results section.

Finally, while the GEE model includes both statistically significant and clinically relevant predictors of postoperative dissatisfaction, one important limitation was the inability to control for lumbar disease. Because the diagnoses are not mutually exclusive, we were unable to separate the patients by pathology for a meaningful subanalysis. As the MSSIC registry matures, this type of analysis could be considered.

\section{Generalizability}

The nature of the MSSIC registry allows for a variety of practice environments with representation of both orthopedic spine surgeons and neurosurgeons. For the most part, the results of our study are widely generalizable to all patients undergoing surgery for degenerative lumbar disorders; however, the results may not be generalizable to spinal pathology that is outside the scope of the MSSIC (trauma, deformity, tumor, and infection). In addition, eligibility for MSSIC requires that a hospital perform at least 200 spine surgeries a year and ideally has representation from both orthopedic surgeons and neurosurgeons. Therefore, these results may not be generalizable to facilities that do not meet this requirement. Lastly, while the MSSIC sampled lumbar operations from 26 sites across the state, only a few centers represent tertiary care referral centers with training programs ( 3 hospitals). The majority of participating providers reflect community-based practices.

\section{Conclusions}

In this MSSIC study of patients who had undergone lumbar spine surgery, the strongest predictors of dissatisfaction were race followed by education. The interplay of depression and chronic pain (symptoms $>1$ year) likely affect postoperative patient recovery and satisfaction. Certain comorbidities such as current smoking and depression affect PROs negatively, although the exact mechanism remains speculative. These findings should serve as a tool for surgeons to identify at-risk populations that may need more attention in terms of effective communication and additional preoperative counseling to address potential barriers unique to their situation.

\section{References}

1. Abdu WA, Lurie JD, Spratt KF, Tosteson AN, Zhao W, Tosteson TD, et al: Degenerative spondylolisthesis: does fusion method influence outcome? Four-year results of the Spine Patient Outcomes Research Trial. Spine (Phila Pa 1976) 34:2351-2360, 2009

2. Adogwa O, Parker SL, Shau DN, Mendenhall SK, Bydon A, Cheng JS, et al: Preoperative Zung depression scale predicts patient satisfaction independent of the extent of improvement after revision lumbar surgery. Spine J 13:501-506, 2013

3. Andersen T, Christensen FB, Niedermann B, Helmig P, Høy $\mathrm{K}$, Hansen ES, et al: Impact of instrumentation in lumbar 
spinal fusion in elderly patients: 71 patients followed for 2-7 years. Acta Orthop 80:445-450, 2009

4. Asher AL, Devin CJ, Archer KR, Chotai S, Parker SL, Bydon M, et al: An analysis from the Quality Outcomes Database, Part 2. Predictive model for return to work after elective surgery for lumbar degenerative disease. J Neurosurg Spine 27:370-381, 2017

5. Bederman SS: Commentary: Patient satisfaction in spinal surgery: should we be addressing customer service or health improvement? Spine J 13:507-509, 2013

6. Celestin J, Edwards RR, Jamison RN: Pretreatment psychosocial variables as predictors of outcomes following lumbar surgery and spinal cord stimulation: a systematic review and literature synthesis. Pain Med 10:639-653, 2009

7. Chang V, Schwalb JM, Nerenz DR, Pietrantoni L, Jones S, Jankowski M, et al: The Michigan Spine Surgery Improvement Collaborative: a statewide Collaborative Quality Initiative. Neurosurg Focus 39(6):E7, 2015

8. Chapin L, Ward K, Ryken T: Preoperative depression, smoking, and employment status are significant factors in patient satisfaction after lumbar spine surgery. Clin Spine Surg 30:E725-E732, 2017

9. Chen BL, Guo JB, Zhang HW, Zhang YJ, Zhu Y, Zhang J, et al: Surgical versus non-operative treatment for lumbar disc herniation: a systematic review and meta-analysis. Clin Rehabil 32:146-160, 2018

10. Chotai S, Devin CJ, Archer KR, Bydon M, McGirt MJ, Nian $\mathrm{H}$, et al: Effect of patients' functional status on satisfaction with outcomes 12 months after elective spine surgery for lumbar degenerative disease. Spine J 17:1783-1793, 2017

11. Cooper G, Lutz GE, Boachie-Adjei O, Lin J: Effectiveness of transforaminal epidural steroid injections in patients with degenerative lumbar scoliotic stenosis and radiculopathy. Pain Physician 7:311-317, 2004

12. Currie SR, Wang J: Chronic back pain and major depression in the general Canadian population. Pain 107:54-60, 2004

13. den Boer JJ, Oostendorp RA, Beems T, Munneke M, Oerlemans M, Evers AW: A systematic review of bio-psychosocial risk factors for an unfavourable outcome after lumbar disc surgery. Eur Spine J 15:527-536, 2006

14. Dyer N, Sorra JS, Smith SA, Cleary PD, Hays RD: Psychometric properties of the Consumer Assessment of Healthcare Providers and Systems (CAHPS $®)$ Clinician and Group Adult Visit Survey. Med Care 50 (Suppl):S28-S34, 2012

15. Elsamadicy AA, Kemeny H, Adogwa O, Sankey EW, Goodwin $\mathrm{CR}$, Yarbrough CK, et al: Influence of racial disparities on patient-reported satisfaction and short- and long-term perception of health status after elective lumbar spine surgery. J Neurosurg Spine 29:40-45, 2018

16. Endler P, Ekman P, Möller H, Gerdhem P: Outcomes of posterolateral fusion with and without instrumentation and of interbody fusion for isthmic spondylolisthesis: a prospective study. J Bone Joint Surg Am 99:743-752, 2017

17. Ervin RB: Prevalence of metabolic syndrome among adults 20 years of age and over, by sex, age, race and ethnicity, and body mass index: United States, 2003-2006. Natl Health Stat Rep 13:1-7, 2009

18. Fenton JJ, Jerant AF, Bertakis KD, Franks P: The cost of satisfaction: a national study of patient satisfaction, health care utilization, expenditures, and mortality. Arch Intern Med 172:405-411, 2012

19. Försth P, Michaëlsson K, Sandén B: Does fusion improve the outcome after decompressive surgery for lumbar spinal stenosis? A two-year follow-up study involving 5390 patients. Bone Joint J 95-B:960-965, 2013

20. Försth P, Ólafsson G, Carlsson T, Frost A, Borgström F, Fritzell P, et al: A randomized, controlled trial of fusion surgery for lumbar spinal stenosis. N Engl J Med 374:1413-1423, 2016
21. Gandhi R, Woo KM, Zywiel MG, Rampersaud YR: Metabolic syndrome increases the prevalence of spine osteoarthritis. Orthop Surg 6:23-27, 2014

22. Gepstein R, Shabat S, Arinzon ZH, Berner Y, Catz A, Folman Y: Does obesity affect the results of lumbar decompressive spinal surgery in the elderly? Clin Orthop Relat Res (426):138-144, 2004

23. Ghogawala Z, Dziura J, Butler WE, Dai F, Terrin N, Magge $\mathrm{SN}$, et al: Laminectomy plus fusion versus laminectomy alone for lumbar spondylolisthesis. N Engl J Med 374:14241434, 2016

24. Godil SS, Parker SL, Zuckerman SL, Mendenhall SK, Devin $\mathrm{CJ}$, Asher AL, et al: Determining the quality and effectiveness of surgical spine care: patient satisfaction is not a valid proxy. Spine J 13:1006-1012, 2013

25. Hooten WM, Knight-Brown M, Townsend CO, Laures HJ: Clinical outcomes of multidisciplinary pain rehabilitation among African American compared with Caucasian patients with chronic pain. Pain Med 13:1499-1508, 2012

26. Ibrahim SA, Siminoff LA, Burant CJ, Kwoh CK: Differences in expectations of outcome mediate African American/white patient differences in "willingness" to consider joint replacement. Arthritis Rheum 46:2429-2435, 2002

27. Kerezoudis P, Alvi MA, Ubl DS, Hanson KT, Krauss WE, Meyer FB, et al: The impact of spine disease, relative to cranial disease, on perception of health and care experience: an analysis of 1484 patients in a tertiary center. J Neurosurg 129:1630-1640, 2018

28. King JT Jr, Moossy JJ, Tsevat J, Roberts MS: Multimodal assessment after surgery for cervical spondylotic myelopathy. J Neurosurg Spine 2:526-534, 2005

29. Laaksonen M, Talala K, Martelin T, Rahkonen O, Roos E, Helakorpi S, et al: Health behaviours as explanations for educational level differences in cardiovascular and all-cause mortality: a follow-up of 60000 men and women over 23 years. Eur J Public Health 18:38-43, 2008

30. LaCaille RA, DeBerard MS, Masters KS, Colledge AL, Bacon W: Presurgical biopsychosocial factors predict multidimensional patient: outcomes of interbody cage lumbar fusion. Spine J 5:71-78, 2005

31. Levin JM, Winkelman RD, Smith GA, Tanenbaum JE, Xiao R, Mroz TE, et al: Emergency department visits after lumbar spine surgery are associated with lower Hospital Consumer Assessment of Healthcare Providers and Systems scores. Spine J 18:226-233, 2018

32. Linn LS, Brook RH, Clark VA, Davies AR, Fink A, Kosecoff $\mathrm{J}$ : Physician and patient satisfaction as factors related to the organization of internal medicine group practices. Med Care 23:1171-1178, 1985

33. Löwe B, Kroenke K, Gräfe K: Detecting and monitoring depression with a two-item questionnaire (PHQ-2). J Psychosom Res 58:163-171, 2005

34. Maher DP, Wong W, Woo P, Padilla C, Zhang X, Shamloo $\mathrm{B}$, et al: Perioperative factors associated with HCAHPS responses of 2,758 surgical patients. Pain Med 16:791-801, 2015

35. Malpani R, Hilibrand AS, Grauer JN: Evolution and use of Hospital Consumer Assessment of Healthcare Providers and Systems (HCAHPS) surveys and their application for spinal surgery patients. Contemp Spine Surg 19:1-6, 2018

36. Memtsoudis SG, Kirksey M, Ma Y, Chiu YL, Mazumdar M, Pumberger M, et al: Metabolic syndrome and lumbar spine fusion surgery: epidemiology and perioperative outcomes. Spine (Phila Pa 1976) 37:989-995, 2012

37. Millward LJ, Lutte A, Purvis RG: Depression and the perpetuation of an incapacitated identity as an inhibitor of return to work. J Psychiatr Ment Health Nurs 12:565-573, 2005

38. Schoenfeld AJ, Lurie JD, Zhao W, Bono CM: The effect of race on outcomes of surgical or nonsurgical treatment 
of patients in the Spine Patient Outcomes Research Trial (SPORT). Spine (Phila Pa 1976) 37:1505-1515, 2012

39. Schoenfeld AJ, Sieg RN, Li G, Bader JO, Belmont PJ Jr, Bono CM: Outcomes after spine surgery among racial/ethnic minorities: a meta-analysis of the literature. Spine J 11:381388,2011

40. Schroeder GD, Coric D, Kim HJ, Albert TJ, Radcliff KE: Are patient-reported outcomes predictive of patient satisfaction 5 years after anterior cervical spine surgery? Spine J 17:943-952, 2017

41. Stewart WF, Ricci JA, Chee E, Morganstein D, Lipton R: Lost productive time and cost due to common pain conditions in the US workforce. JAMA 290:2443-2454, 2003

42. US Department of Health and Human Services: 2011 Report to Congress: National Strategy for Quality Improvement in Health Care. Rockville, MD: Agency for Healthcare Research and Quality, 2011 (https://www.ahrq. gov/workingforquality/reports/2011-annual-report.html) [Accessed September 17, 2019]

43. Weinstein JN, Lurie JD, Tosteson TD, Skinner JS, Hanscom B, Tosteson AN, et al: Surgical vs nonoperative treatment for lumbar disk herniation: the Spine Patient Outcomes Research Trial (SPORT) observational cohort. JAMA 296:2451-2459, 2006

44. Weinstein JN, Tosteson TD, Lurie JD, Tosteson AN, Hanscom B, Skinner JS, et al: Surgical vs nonoperative treatment for lumbar disk herniation: the Spine Patient Outcomes Research Trial (SPORT): a randomized trial. JAMA 296:24412450, 2006

45. Zakaria HM, Mansour T, Telemi E, Xiao S, Bazydlo M, Schultz L, et al: Patient demographic and surgical factors that affect completion of patient-reported outcomes 90 days and 1 year after spine surgery: analysis from the Michigan Spine Surgery Improvement Collaborative (MSSIC). World Neurosurg 130:e259-e271, 2019

\section{Disclosures}

Dr. Chang receives research funding from Medtronic, who was not specifically involved in this project. He is also a consultant for
Globus Medical, K2M, and SpineGuard. Dr. Park is a consultant for Globus, NuVasive, and Allosource and receives royalties from Globus. Although Blue Cross Blue Shield of Michigan (BCBSM) and MSSIC work collaboratively, the opinions, beliefs, and viewpoints expressed by the authors do not necessarily reflect the opinions, beliefs, and viewpoints of BCBSM or any of its employees. Support for MSSIC is provided by BCBSM and Blue Care Network as part of the BCBSM Value Partnerships program.

\section{Author Contributions}

Conception and design: Chang. Acquisition of data: Macki, Alvi, Kerezoudis, Xiao, Schultz, Bazydlo, Bydon, Park. Analysis and interpretation of data: Macki, Alvi, Kerezoudis, Xiao, Schultz, Bazydlo, Bydon, Park. Drafting the article: Macki. Critically revising the article: Chang, Macki. Reviewed submitted version of manuscript: Chang, Macki, Kerezoudis, Schultz. Study supervision: Chang, Park.

\section{Supplemental Information Previous Presentations}

This work was presented as an oral podium discussion at the Congress of Neurological Surgeons (CNS) Annual Meeting held in Houston, Texas, on October 6-10, 2018.

\section{Correspondence}

Victor Chang: Henry Ford Hospital, Detroit, MI. vchang1@ hfhs.org. 